\title{
Low Carbon Mobility Transitions and Justice: A Case of Costa Rica
}

\author{
Deepak John ${ }^{1} \cdot$ Ehsan Derakhshi ${ }^{1}$
}

Published online: 28 February 2022

(c) Society for International Development 2022

\begin{abstract}
This research article analyzes the electrification of light-duty vehicles and its implications on equity and justice paradigm within a pro-green policy environment. The case of Costa Rica is investigated as the country has already gained considerable momentum in decarbonizing its economy and considers the transportation as the next step in its sectoral transformation. We evaluate the transition through different lenses of sustainability, equity and justice using socio-technical system transition and the energy justice frameworks. The outcome of the analysis is compared with the existing policies and plans for transport decarbonization in Costa Rica. The findings suggest that (a) the country should foster industry-academia collaborations and engagements to fortify knowledge sharing networks for low-mobility innovation, (b) subsidization of electricity cost for electric vehicles seems essential to incentivize market pull, and (c) Costa Rica should proceed towards the creation of domestic and local electric vehicles manufacturing capacity to provide an industrial environment for building long-standing technological learning and accumulation.
\end{abstract}

Keywords Net-zero mobility $\cdot$ Sustainability $\cdot$ Socio-technical transitions $\cdot$ Just transitions $\cdot$ Sustainable development $\cdot$ Low-carbon transitions

\section{Transitions for Whom?}

In the current global political scenario, the push for energy transitions has been notably high due to the global imperative for accelerating climate efforts. The COP26 had a series of net-zero declarations by different nation-states and the list is growing. As many stronger developing countries like China and India put in their respective targets, there is surmounting pressure on other developing nations to declare their net-zero positions on climate goals. Many of the governments have put together individual climate action plans to mitigate climate impacts. Although Nationally Determined Contributions (NDCs) are framed by looking inwards based on a country's capabilities and capacities, projecting netzero ambitions requires much more.

Generally, much of the discourse on net-zero efforts remains hinged on decarbonizing the country's energy supply systems and bringing renewables into the energy mix. Although energy supply systems of the future need to

Deepak John

D.John@sussex.ac.uk

1 Sussex Energy Group, Science Policy Research Unit, University of Sussex, Brighton, UK accommodate the future needs and aspirations of its people, it also needs to consider how aspirations may change their choices, demand and behaviour over time. These forthcoming changes at the point of energy use will have a much more visible and direct bearing on the user. It boils down to their interactions with end-use technology; what they may have access to, or more importantly how affordable is it?

Hence, the net-zero ambitions come with high cost, not just from a financial, but also equity point of view. These transformations must be handled sensitively and delicately, as existing systems are deep-rooted in society and culture with decades of technological, cultural and discursive lockins. One of the classic examples of these lock-ins is to be found in the transportation sector. The transportation sector has been steeped in almost 200 years of a carbon-intensive regime of fossil-based fuels. Despite efficiency improvements, electrification and the use of biofuels, road transportation alone accounted for $24 \%$ of total emissions in 2019 (IEA 2021). Many countries such as Costa Rica have put forth forward-looking policies to tackle the situation and move into a low carbon mobility paradigm. 


\section{Costa Rica's Road to Decarbonization}

Costa Rica has put forward its best foot to strive for a carbon-neutral economy. With its huge biodiversity (Embassy of Costa Rica in Washington DC 2022) and abundance of natural resources, Costa Rica has always been known for its 'environment-friendly' policies (United Nations 2019). Almost $99 \%$ of its energy supply is sourced from renewable sources, much of it by tapping its network of hydropower which provides baseload power (IHA 2019). Having turned much of its energy supply 'green', Costa Rica sits at a cusp of an opportunity to transform its energy demand-side—primarily focused on decarbonizing its transportation sector.

With a growing economy and appetite for private transportation, Costa Rica, with 175 passenger cars per 1000 people (Helgi Library 2021) is ranked first in Central America. Despite other sectors, transportation still contributed vastly to GHG emissions with more than $40 \%$ of total emissions in 2016 (Our World in Data 2021). The country also suffers from traffic congestion and air pollution due to this (IDB 2020). Hence, the net benefits of decarbonizing and net reduction in carbon emissions from this sector are quite high, as can be seen in Fig. 1.

Costa Rica had charted out an ambitious plan to decarbonize its entire economy by 2050 in its National Decarbonization Plan (NDP) (Government of Costa Rica 2018).
Among the ten decarbonization axes of NDP, it prioritized public transport, light-duty vehicles and freight transportation as the top three decarbonization axes for action. However, it is also important to understand how the existing socio-political factors in the country are placed to convert this opportunity into a reality. Sustainability transitions in such large technical systems are often explored using a transition framework called the Multilevel Perspective (MLP) (Geels 2012).

\section{Mobility Transition for Costa Rica}

Transportation is considered a socio-technical system with evolutionary characteristics with various path dependencies (Geels 2012). It suggests that the vestiges of existing social, cultural, and economic structures of transportation play a role in defining the future pathway of transportation in the country. The MLP provides useful heuristics to understand the possible extent of success of this transitional endeavour.

The MLP framework corresponds to dynamic interactions between three different levels: niches, regimes and landscapes. The niches are spaces that shield, protect and nurture any innovation activity; a socio-technical regime represents an existing and established network of actors, groups, rules, institutions and related technical material elements; and landscape refers to exogenous events and trends such as political developments, deep cultural and societal

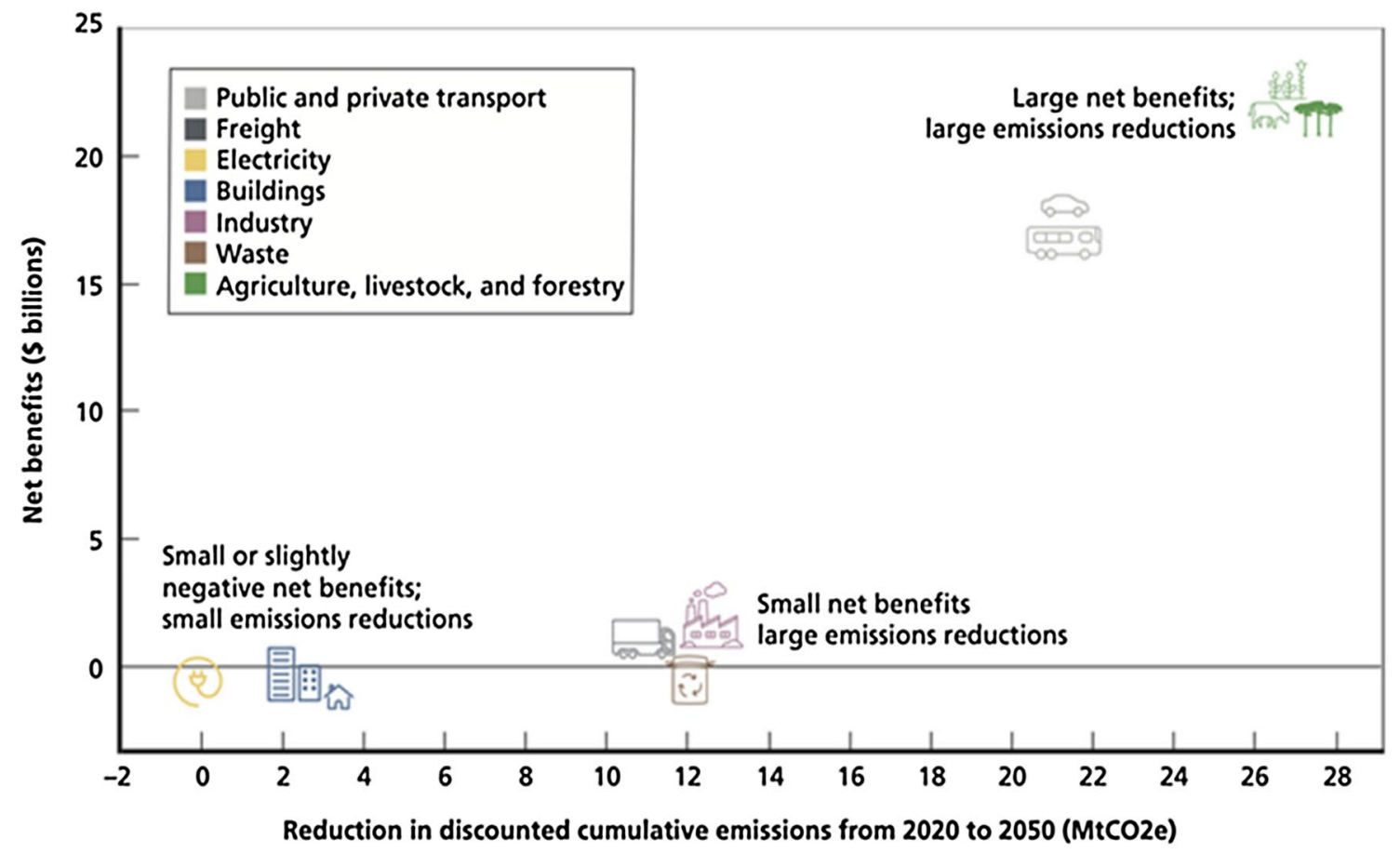

Fig. 1 Benefits and costs of decarbonizing CR's economy (IDB 2020) 
values, climate change and others, which does not change in the short run (Geels 2012). MLP posits that processes at the interface of niche, regime and landscape must be aligned to make a sustainability transition.

\section{Sociotechnical Landscape}

The landscape exerts both stabilizing and destabilizing pressure on the regime. In Costa Rica, the agenda of climate change has been quite high ranking in its policy priorities. As mentioned earlier, it is one of the few countries having a well-laid out plan for action in achieving decarbonization goals. Hence, the political economy of climate change agenda can clearly sow the seeds of destabilization within the regime. Another crucial factor is the notion of 'peak oil' which is a key determinant as it deals with the inevitable idea of oil depletion. However, although CR has notoriously high fuel prices in Central America (Quirós-Tortós et al. 2019), the oil security seems firmly dependent on US oil, importing $80 \%$ of total oil requirements (OEC 2021). It may also be prudent to visit a rising feature of current society that has a destabilizing influence on the regime-the 'rise of information society'. The diffusion of online technologies has dispensed away the need for private vehicles for shopping or working. Costa Rica even has a teleworking law that predates the COVID-19 working paradigm (CINDE 2019).

On the other hand, stabilizing forces such as cultural preferences for car ownership remain high in Costa Rica, primarily fueled by poor public transport modalities and unsuitable urban planning (Pisu and Villalobos 2016). Similarly, long-term material elements of transport infrastructure are attuned to the fossil-fuel-based car usage patterns and behaviour. The favourable nudges of consumerist society further entrench the existing regime of car ownership to persist (Freund and Martin 2000). Figure 2 gives a diagrammatic representation of the stabilizing and destabilizing pressures on the automobility landscape.

\section{Sociotechnical Regime}

Withstanding other smaller interest groups, the major actor group comprising the regime include the policymaker, the auto-industry body or association, and the consumers.

As previously mentioned, the policymakers have a strong political will and intent to make the transition happen. The vision for this energy transition has manifested in the NDP document. The multilateral and bilateral organizations have bought into this vision and are supporting policymakers (GIZ 2021) with finance and technical assistance. Francisco Alpízar, an economist at the Tropical Agriculture Research and Higher Education Centre in Turrialba and a climate adviser to the Costa Rican government has said that 'If we can't pull it off by 2050, it's likely no other country can pull it off, that would be really bad' (Sengupta and Villegas 2019). Hence the policy apparatus is strongly oriented to make this transition.

The automobile industry body on the other hand, is poorly poised to take advantage of the changing policy landscape. This is primarily due to the almost non-existent domestic auto manufacturing in the country (U.S. Department of Commerce 2021). Being import heavy, the opportunities for the EV market to build over existing channels of manufacturing, managing and marketing seem limited. It presents a market barrier for EV market development due to lack of dealership, importers or an optimized supply chain. The product cycle theory (Vernon 1966) suggests that the closer proximity to inputs, technical and organizational knowledge will help in the innovation and diffusion of EV within the markets and society. At this point, this seems to suggest that the auto industry has a weak polarization to make this transition happen. It indicates a weak capability of assimilating and contextualizing the EV technology for its requirements.

The intent and attitude of the consumer group lie in between the policymaker and the auto industry group. There has been a continuation of combustion vehicles, the average age being 15 years compared to 7.4 and 11.6 years in Europe

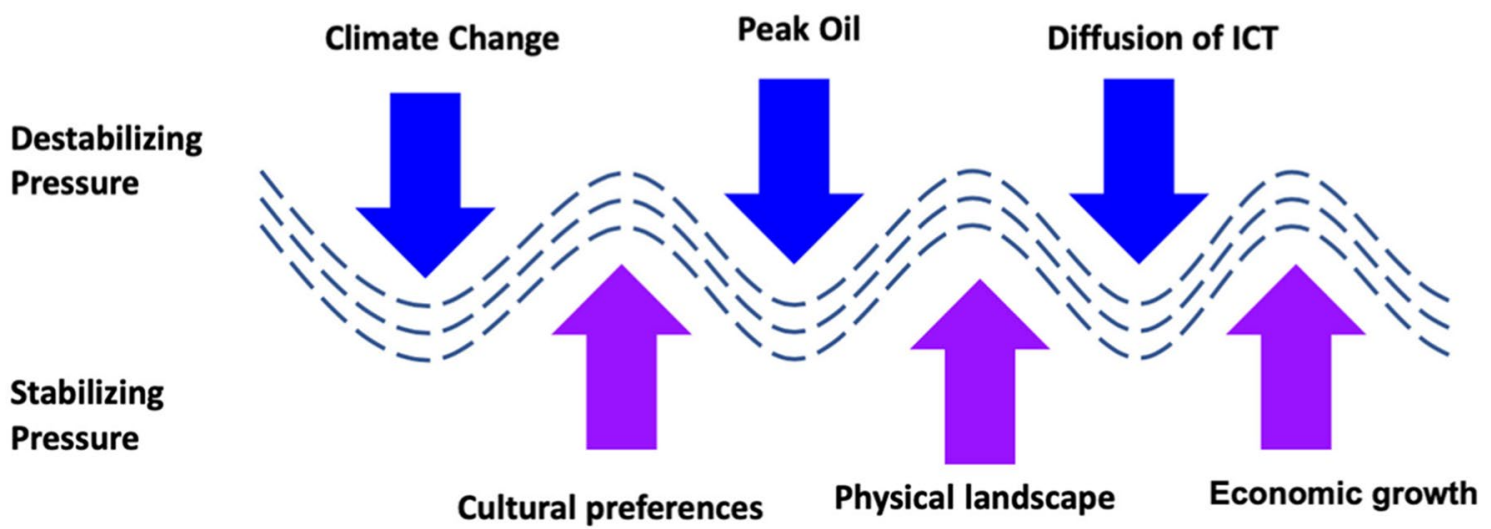

Fig. 2 Landscape pressures in automobility regime, Adapted from Geels (2012) 
and the USA respectively (Government of Costa Rica 2018). However, there has been an attitude preference shift for purchasing electric vehicles (Utgård and Araya 2016). There has been a rise of citizen coalitions, collectives, and consortia supporting this transition; hence a fair polarization can be assigned for the same. The net-polarization of the regime system as represented in Fig. 3 portends the formation of a weak destabilization as three actors interact dynamically with each other.

\section{Innovations Niches}

Forming the third and the last piece of the MLP puzzle is finding appropriate technological innovations that support this transition. Low-carbon innovation technology such as Electric Vehicle (EV), Charging Infrastructure and Smart Grids do not operate in vacuum or isolation but are dynamically interacting with each other as in the Fig. 4.

For a country that is dependent on variable energy generation, it is important to have smart grids in place. It also builds demand balancing capabilities for the system when demand for electric mobility comes online. The government has connected to the smart grid a series of charging stations, forming the backbone of the charging infrastructure. Costa Rica started off well in this regard by being the first country in Latin America to have a national charging network (Zúñiga 2020). For electric cars, the demand saw a rise of import rate by 23\% (U.S. Department of Commerce 2021), however considering the country has the highest density of cars (Shah 2020), EV is still a fraction.

\section{Equity Implications of Regime Actors}

There have not been many studies to understand the justice implications of mobility transitions, however, Sovacool et al. (2019) study on Nordic electric transitions provide a useful method to analyze through various lenses of distributional justice, recognition justice, procedural justice and

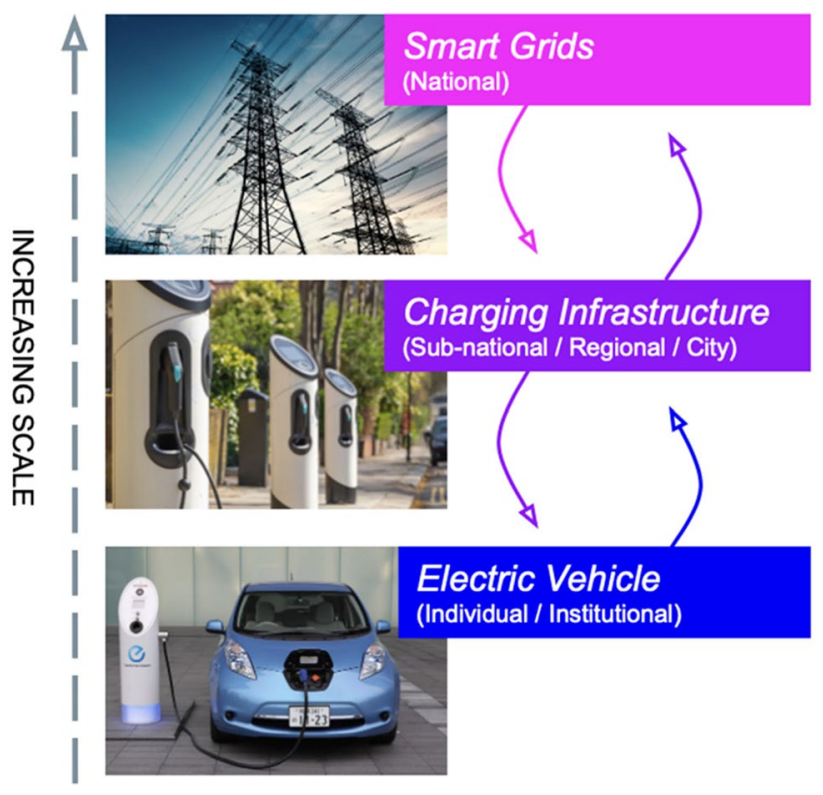

Fig. 4 Scale-dependent dynamic interaction between innovation niches

cosmopolitan justice. In this essay, these justice lenses are enmeshed and applied to MLP regime actors as mentioned in the previous section. The three actors-Consumers, Policymakers and Auto-industry can inadvertently take on roles of the one either perpetrating these transition injustices or becoming the victims of it.

Figure 5 shows an elaborate causal network for injustice pathways for the regime actors. The injustice pathways for consumers can be pointed to the high cost of electricity (Quirós-Tortós et al. 2019) in Costa Rica which will affect the charging cost of EV. Similarly, there is an agglomeration of charging infrastructure within urban areas (EESI 2021) which limits the scope of its usage of people outside the urban landscape. Given that EVs are considered as a luxury good with a high price tag, there is a relatively lower recognition of how affordable the technology is to different sections of society. The decisions of where

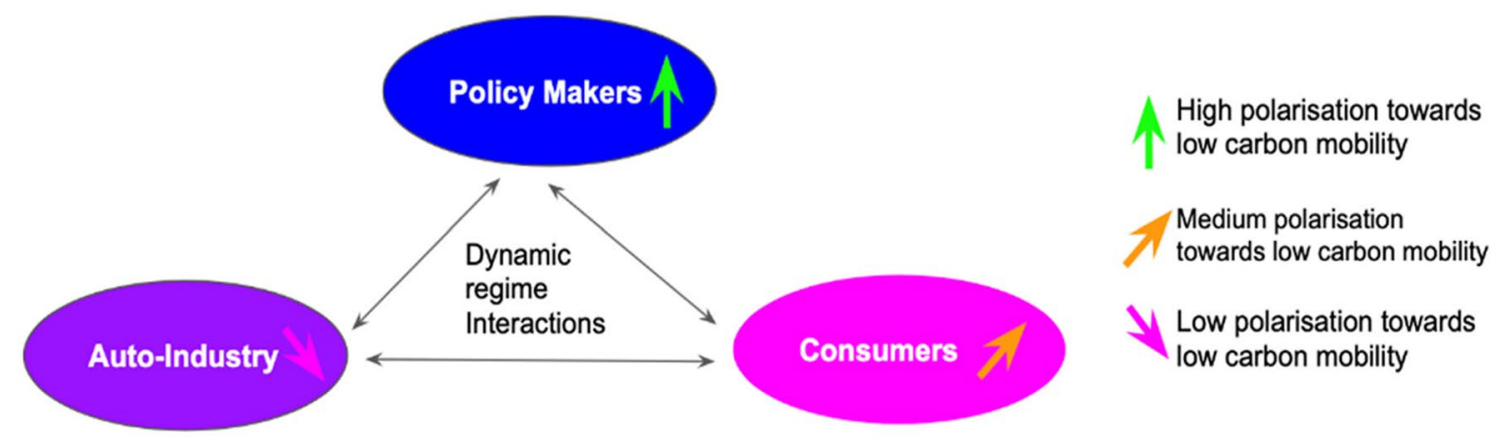

Fig. 3 Dynamic regime interactions in Costa Rica light-duty vehicle industry 


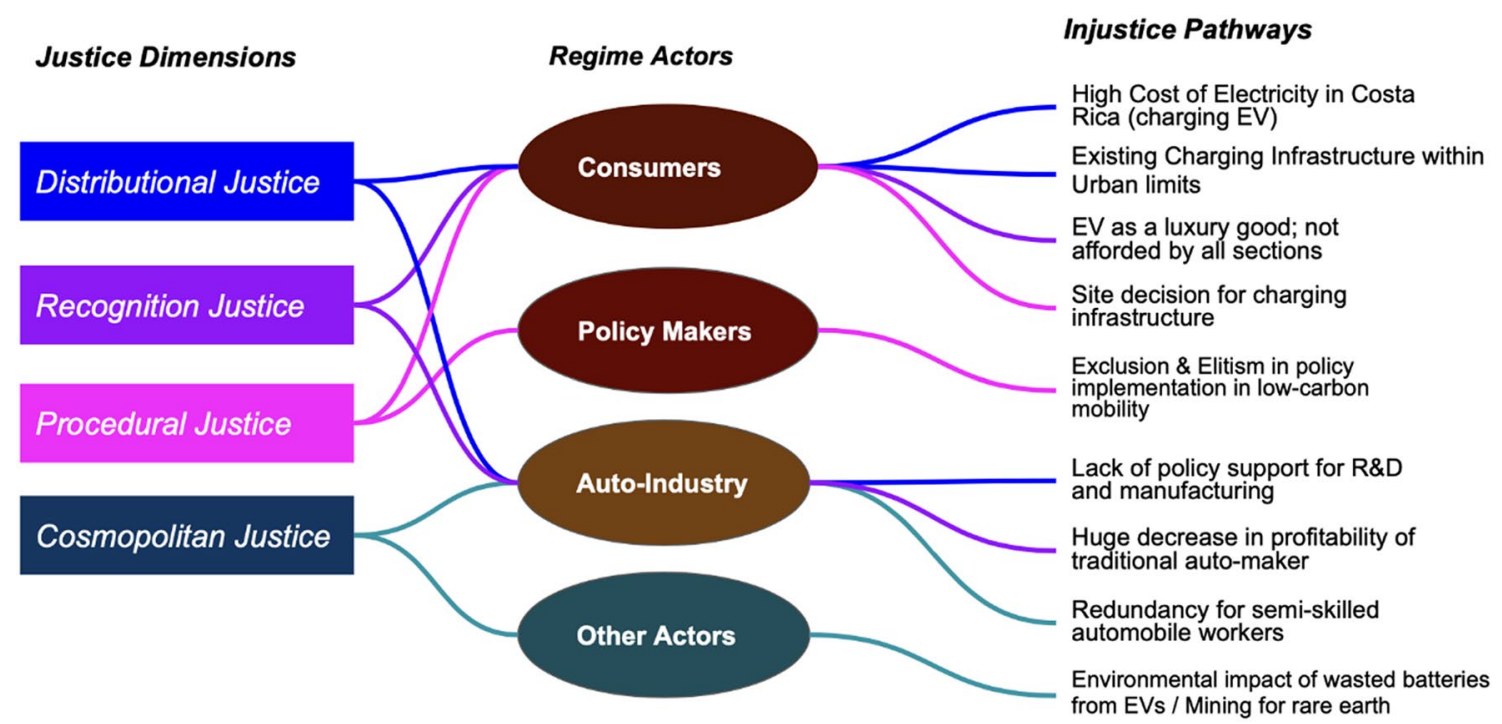

Fig. 5 Perpetrators and victims of low carbon mobility transition in Costa Rica

to place charging infrastructure, what process was followed for consulting, and how it was done indicate laxity in the due process followed. Hence consumer groups fall victims to a range of injustices under the distributional, recognition and procedural dimensions as presented in Table 1.

The auto industry also has its failings owing to transition pressures. The supporting ecosystem for providing sufficient resources and setting up incentive structures for carmakers for transition has been inadequate (IEA 2018) Apparently, the traditional automakers and assemblers see decreases in profit due to additional capital investment in manufacturing electric product line-ups as well as the cost involved in skill manpower retraining-there is lesser recognition of this. One of cosmopolitan injustices pathways falls on third party semi-skilled workers, the skills will become redundant with no income safety nets. In general, the automaker group also fall victims to issues of distributional, procedural and cosmopolitan justices. The last group of policymakers, with sufficient power and resources for transitions, enforce policies for accelerating transitions and may trample on elements of procedural justice in its rush for gaining a higher sustainability goals. This reasonably allows for unintentional perpetration of recognition and procedural injustice.

Table 1 Different justice dimension set and roles for all regime actors

\begin{tabular}{lll}
\hline Regime factor & Justice dimension set & Assumed role \\
\hline Consumer & $(\mathrm{D}, \mathrm{R}, \mathrm{P})$ & Victim \\
Policy maker & $(\mathrm{R}, \mathrm{P})$ & Prepetrator \\
Auto-industry & $(\mathrm{D}, \mathrm{R}, \mathrm{C})$ & Victim \\
\hline
\end{tabular}

$D$ Distributional Justice, $R$ Recognition Justice, $P$ Procedural Justice and $C$ Cosmopolitan Justice

\section{Emerging Window of Opportunity?}

The concerns for climate change and the agenda to address it, creates a pressure for a substantial change in carbonemitting sectors in Costa Rica including fossil fuel-based transportation. At the same time, a rising reconfiguration and realignment amongst the actors, primarily spearheaded by policymakers is forming to favour the transition. The combination of climate change pressure and the overall interest of actors for changing the current regime, creates a 'window of opportunity' for transition soon. However, the emerging regime may be weak in its nature, and the window of opportunity will not be resilient against future confrontations resisting change, unless effective and rapid measures are taken to foster the transition successfully.

Although they are tightly co-dependent on each other, niche innovations have different potency for leaping into the window of opportunity. Smart Grids, primarily driven by the policy intent of diversifying the energy mix of the country have taken off positively with increasing implementation targets. However, EVs seem to lack sufficient push to take the leap for two major reasons; first, due to the weak domestic auto-manufacturing landscape in Costa Rica, the industry lacks sufficient technological capabilities to make the transition happen (U.S. Department of Commerce 2021); Second, the national system of innovation of Costa Rica reveals weakness in actors' endeavours and connections among them. According to Pisu and Villalobos (2016) compared with OECD nations, Costa Rica lacks adequate academic research and publication in the field, public and private $R \& D$ expenditure, patenting legal frameworks, venture capital support, and networks resulting in futile knowledge creation and sharing to build the appropriate environment for the EV 
transition. Moreover, it can be inferred that the collaborations between industry-academia hardly happen under the current environment (Cubillo 2021).

Furthermore, the charging stations and EV present a classic chicken and egg paradox (Shi et al. 2021). Although the policymakers have taken up charging infrastructure as a 'public good' with a national charging grid, it is ineffective for wider market uptake and building resilient business models, especially if the network is extended to peri-urban and rural areas. On the other hand, the development of EV requires accessible and affordable charging infrastructure all around the country. Hence charging infrastructure has a high dependency on the diffusion and adoption of $\mathrm{EV}$ within Costa Rican society and vice versa, limiting the chance of diffusion for both.

\section{Final Words}

In order that EV uptake improves and consequently increase in charging infrastructure, Costa Rica should uplift the market demand for EVs by removing barriers facing consumers. In this regard, the subsidization of electricity cost for EVs is essential to incentivize the market pull. This intervention is also important for addressing the distributional justice and affordability of running EVs in CR. On the other hand, the country has suffered a large budget deficit (OECD 2020a). Therefore, financial buy-in from multilateral and bilateral donors would be the key to materializing this proposal.

To address the gaps and support the sustainable transition, strong and concrete policy commitment is crucial. Costa Rica can do good to improve industry-academia collaborations and engagements to fortify knowledge-sharing networks for low-mobility innovation. Costa Rica will have to gear up the creation of domestic and local EV manufacturing capacity to provide an industrial environment for fostering long-standing technological learning. This development would ensure Costa Rica's sustainable technological accumulation in the long term, instead of an import-dependent lock-in situation (OECD 2020b).

\section{References}

CINDE. 2019. https://www.cinde.org/en/essential-news/costa-ricaworkfromhome-bill-signed-into-law. Costa Rican investment Promotion Agency (CINDE). https://www.cinde.org/en/essentialnews/costa-rica-workfromhome-bill-signed-into-law. Accessed 20 January 2022.

Cubillo, Paulo Ruiz. 2021. Interview with Paulo Ruiz Cubillo. Edited by R. Sugioka.

EESI. 2021. Beyond Cities: Breaking Through Barriers to Rural Electric Vehicle Adoption. Environmental and Energy Study Institute
(EESI). https://www.eesi.org/articles/view/beyond-cities-break ing-through-barriers-to-rural-electric-vehicle-adoption. Accessed 26 January 2022.

Embassy of Costa Rica in Washington DC. 2022. Environment. http:// www.costarica-embassy.org/index.php?q=node/12. Accessed 22 January 2022.

Freund, Peter, and George Martin. 2000. Driving South: The globalization of auto consumption and its social organization of space. Capitalism Nature Socialism 11: 51-71. https://doi.org/10.1080/ 10455750009358940.

Geels, Frank W. 2012. A socio-technical analysis of low-carbon transitions: introducing the multi-level perspective into transport studies. Journal of Transport Geography 24: 471-482. https://doi.org/ 10.1016/j.jtrangeo.2012.01.021. https://www.sciencedirect.com/ science/article/pii/S0966692312000269.

GIZ. 2021. Sustainable urban transport: Avoid-shift-improve. Deutsche Gesellschaft für Internationale Zusammenarbeit (GIZ). https:// www.giz.de/en/worldwide/62687.html. Accessed 22 January 2022.

Government of Costa Rica. 2018. National Decarbonization Plan (NDP). Government of Costa Rica.

Helgi Library. 2021. Passenger Cars Per 1,000 People in Costa Rica. https://www.helgilibrary.com/indicators/passenger-cars-per-1000people. Accessed 20 January 2022.

IDB. 2020. The benefits and costs of decarbonizing Costa Rica's economy: Informing the Implementation of Costa Rica's National Decarbonization Plan under Uncertainty. Inter-American Development Bank (IDB).

IEA. 2018. Law 9518 - Incentives and promotion for electric transport. International Energy Agency (IEA). https://www.iea.org/policies/ 2973-law-9518-incentives-and-promotion-for-electric-transport.

IEA. 2021. Transport: Improving the sustainability of passenger and freight transport. International Energy Agency (IEA). https:// www.iea.org/topics/transport. Accessed 19 January 2021.

IHA. 2019. Country Profile: Costa Rica. The International Hydropower Association (IHA). https://www.hydropower.org/country-profiles/ costa-rica. Accessed 20 January2022.

OEC. 2021. Refined Petroleum in Costa Rica. The Observatory of Economic Complexity (OEC). https://oec.world/en/profile/bilat eral-product/refined-petroleum/reporter/cri. Accessed 20 January 2022.

OECD. 2020a. Enhancing business dynamism and consumer welfare with regulatory reform. Organisation for Economic Co-operation and Development (OECD).

OECD. 2020b. OECD Economic Surveys: Costa Rica 2020b. Organisation for Economic Co-operation and Development (OECD).

Our World in Data. 2021. Costa Rica: CO2 Country Profile. https:// ourworldindata.org/co2/country/costa-rica. Accessed 20 January 2022.

Pisu, Mauro, and Federico Villalobos. 2016. A bird-eye view of Costa Rica's transport infrastructure. OECD Economics Department Working Papers, No. 1323, OECD Publishing, Paris, https://doi. org/10.1787/5jlswbwvwqjf-en.

Quirós-Tortós, Jairo, Luis Victor-Gallardo, and Luis Ochoa. 2019. Electric Vehicles in Latin America: Slowly but Surely Toward a Clean Transport. IEEE Electrification Magazine 7 (2): 22-32. https://doi.org/10.1109/MELE.2019.2908791.

Sengupta, Somini, and Alexander Villegas. 2019. Tiny Costa Rica Has a Green New Deal, Too. It Matters for the Whole Planet. The New York Times. https://www.nytimes.com/2019/03/12/climate/costarica-climate-change.html.

Shah, Reena. 2020. Costa Rica's answer to range anxiety. BBC. https:// www.bbc.com/future/article/20210928-costa-ricas-answer-torange-anxiety. Accessed 20 January 2022.

Shi, Lefeng, Ying Hao, Shengnan Lv, Liana Cipcigan, and Jun Liang. 2021. A comprehensive charging network planning scheme for 
promoting EV charging infrastructure considering the ChickenEggs dilemma. Research in Transportation Economics 88: 100837. https://doi.org/10.1016/j.retrec.2020.100837. https:// www.sciencedirect.com/science/article/pii/S0739885920300263.

Sovacool, Benjamin K., Johannes Kester, Lance Noel, and Gerardo Zarazua de Rubens. 2019. Energy Injustice and Nordic Electric Mobility: Inequality, Elitism, and Externalities in the Electrification of Vehicle-to-Grid (V2G) Transport. Ecological Economics 157: 205-217. https://doi.org/10.1016/j.ecolecon.2018.11.013. https://www.sciencedirect.com/science/article/pii/S092180091 8307602.

U.S. Department of Commerce. 2021. Costa Rica Electric Vehicles. The International Trade Administration, U.S. Department of Commerce. https://www.trade.gov/market-intelligence/costa-rica-elect ric-vehicles. Accessed 20 January 2022.
United Nations. 2019. Champion of the Earth: Costa Rica. https://www. unep.org/championsofearth/laureates/2019/costa-rica.

Utgård, Bjørn, and Mónica Araya. 2016. Pura Vida! Driving Smart Electric Mobility in Costa Rica. https://elbil.no/pura-vida-drivi ng-smart-electric-mobility-in-costa-rica.

Vernon, Raymond. 1966. International Investment and International Trade in the Product Cycle*. The Quarterly Journal of Economics 80 (2): 190-207. https://doi.org/10.2307/1880689.

Zúñiga, Alejandro. 2020. Costa Rica says it's the first country in the region with nationwide electric vehicle charging grid. The Tico Times. https://ticotimes.net/2020/02/27/costa-rica-says-its-thefirst-country-in-the-region-with-nationwide-electric-vehicle-charg ing-grid. Accessed 20 January 2020.

Publisher's Note Springer Nature remains neutral with regard to jurisdictional claims in published maps and institutional affiliations. 